\title{
Clinical Practice and Epidemiology

\section{Psychoeducational intervention and prevention of relapse among schizophrenic disorders in the Italian community psychiatric network}

\author{
Eugenio Aguglia*1, Elisabetta Pascolo-Fabrici ${ }^{1}$, Francesca Bertossi ${ }^{1}$ and \\ Mariano Bassi ${ }^{2}$
}

Address: ${ }^{1}$ Psychiatric Clinic of the University of Trieste, Via Paolo De Ralli 5, 34126, Trieste, Italy and ${ }^{2}$ Mental Health Department, Local Health Unit, AUSL Via Castiglione 29, 40124 Bologna, Italy

Email: Eugenio Aguglia* - e.aguglia@fmc.units.it; Elisabetta Pascolo-Fabrici - e.pascolo@fmc.units.it;

Francesca Bertossi - bertossi.francesca@libero.it; Mariano Bassi - tarpon8349@libero.it

* Corresponding author

Published: 25 June 2007

Clinical Practice and Epidemiology in Mental Health 2007, 3:7 doi:10.1 I86/1745-0179-37

This article is available from: http://www.cpementalhealth.com/content/3/I/7

(C) 2007 Aguglia et al; licensee BioMed Central Ltd.

This is an Open Access article distributed under the terms of the Creative Commons Attribution License (http://creativecommons.org/licenses/by/2.0), which permits unrestricted use, distribution, and reproduction in any medium, provided the original work is properly cited.
Received: 27 November 2006 Accepted: 25 June 2007

\begin{abstract}
Background: The lack of compliance is associated with an increased risk of hospitalization and switching or augmentation of therapy when compared with being compliant. A synergy of drug therapy and psychosocial interventions can give more benefits in treatment.

Methods: A perspective study was conducted on I 50 patients with schizophrenia over I 5 centers in Italy. The experimental group was treated with drug therapy, traditional psychosocial and psychoeducation for the patients and their families, while the control group received traditional psychosocial and drug intervention over I year.

Results: The experimental group showed a significant statistical improvement $(p<0,05)$ in almost all the scales that have been assessed (BPRS, SAPS, SANS, SIMPSON-ANGUS SCALE, LANCASHIRE QL SCALE). Significant was the reduction of the number of hospitalizations and of days of hospital stay.
\end{abstract}

Conclusion: As it is shown in international literature, psychoeducational intervention with schizophrenic patients and their families can reduce the occurrence of relapse.

\section{Background}

The recent changes in the treatment of schizophrenic disorders allow us to use both traditional and atypical antipsychotic drugs, and psychosocial interventions with a reliable efficacy, in treating the symptoms of both positive and negative schizophrenia [1-11].

The clear aim of the treatment of such disorders is not only to control the symptoms, but it is also to prevent new symptomatic acute phases, to bring the patient to comply with the prescribed treatment plan, to restore a certain social and working functioning and to reach a better quality of life.

Among the psychosocial interventions, the psychoeducational ones for the patients and their family, have been considered to be the most promising and successful within the last thirty years [12-14]. 
The basic principles of the psychoeducational interventions are represented by simple, correct and complete information about the disorder and its possible treatment methods [15].

The goal is also to try to make both the patients and their family aware of those problems, which are related with the disorder, the communication difficulties and the most appropriate management of the stressors and life events.

All of these elements allow the patients and their family to become more conscious and better able to deal with problems, fostering therefore an easier and more effective course of the illness, especially when the psychoeducational interventions are associated with an appropriate and long-term drug treatment $[11,16]$.

A review of those studies published in this field since the beginning of the 1980s, confirms that the use of psychosocial treatments and combined with an appropriate long term antipsychotic therapy, can reduce the percentage of relapse [17] in a year to about 54\%. If psychoeducational interventions are carried out with patients and their families [18], in addition to this assertive community approach, the yearly relapses further decrease to $27 \%$ [19].

These psychoeducational interventions follow a cognitive-behavioral model. This was probably one of the main causes for the difficult and slow acceptance and popularity of such new therapeutic interventions by the Italian community mental health centers. In fact, still today, despite their overwhelming success rate and their spread among many psychiatric staffs in the world, the psychoeducational approaches are still viewed with suspicion, and many Italian psychiatrists are openly against them. The open and latent fear is accepting therapeutic models which appear to be too simple and limiting, oriented more toward a biological approach of the disorder, which is far from the Italian mental health community and tradition. On the other hand, most of psychiatrist in Italy have adopted a psychodynamic oriented approach, though filtered through the requirements established by social psychiatry and by the "setting" of the public psychiatric services after the Basaglia reform. Often, the idea of introducing new treatment techniques with the most critical patients and their family members is viewed as an attack to already consolidated effective procedures and to rooted cultural models [20].

However, the total effectiveness of the psychoeducational interventions cannot be disputed: in fact more than 20 researches around the world have demonstrated the effectiveness and the encouraging cost-benefit relationship [21-26] for a group of more than 1500 patients [27].
The positive effects of such psychoeducational intervention on the patients and their family, are not only a decrease of new symptomatic acute phases, but also a decrease of the number of hospitalizations and a better compliance with the treatment [27] especially the drug one [1,29-33].

It is generally believed that people affected by schizophrenia that regularly take prescribed antipsychotic drugs, show a faster and more complete remission, and a lower risk of relapse [34].

Since the 1970s, many studies have confirmed that the participation in a long term and stable drug treatment can better prevent relapse compared to a more irregular and discontinuous drug treatment. However, unfortunately, only $50 \%$ of people affected by schizophrenia undergo regular an adequate drug treatments for a set period of time $[35,36]$.

On the other hand it is generally agreed that not all patients respond the same to drug treatments and that those treatments do not show the same results with every patient [37].

In many cases the benefits of such drug treatment are only partial and therefore they are not very well liked by the patients and by their families [38].

Several studies have shown that approximately one-third of patients are fully compliant, one-third partially compliant, and the final one third entirely non-compliant. [3941].

Another study demonstrated that $54,5 \%$ of patients were compliant and that $39,0 \%$ were partially compliant. Partial compliance was associated with an increased risk of hospitalization and switching or augmentation of therapy when compared with being compliant [42].

A decrease in compliance predicted an increase in PANSS which corresponds to a worsening of symptoms [43].

A low compliance also predicts an increase risk of hospitalization: even small gaps in therapy (1-10 days) increased the likelihood of hospitalization by twice, whereas larger gaps in therapy ( $>30$ days) increased the likelihood of hospitalization by four times [43].

The psychoeducational interventions can facilitate schizophrenic patients in gaining the necessary skills to effectively manage a drug treatment.

In order to have the patient comply to an antipsychotic drug treatment in a more appropriate way, it is necessary 
to: 1) assess thoroughly the patient's background in terms of past drug therapies and of those factors which might have prevented the compliance; 2) use, whenever it is possible, a "contractual" approach, in which any potential change from its original layout can easily be discussed with the patient; 3 ) educate the patients and the family members on the disorder and its characteristics, and on the prevention of potential relapses, making them aware of the risks and the benefits of antipsychotic drugs; 4) maintain, whenever it is possible, the control over those patients who may temporarily neglect and/or refuse the drug treatment, still offering them alternative solutions $[1,44]$.

Informative, short term psychoeducational interventions seem to be not as effective in the long run, in maintaining the compliance[28,45-47].

On the other hand, a more structured and prolonged psychoeducational treatment for patients and their families, seem to be more effective in the long run $[4,10,48-53]$.

\section{Methods}

\section{I Design of the study}

This study was conducted in Italy, with the goal of trying to identify the most effective tools in the prevention of relapse among those affected by schizophrenia.

The main objective of the study was to assess the effectiveness of the combination of a long term drug therapy and a psychoeducational intervention, on people affected by schizophrenia in reducing relapses in terms of number of hospitalisations and clinical parameters.

The Italian protocol was developed based on the model of a study conducted in Munich between 1990 and 1994, by Kissling and Bauml, with a sample of 236 patients [1,54].

In this study, half of the patients affected by schizophrenia underwent a traditional drug treatment (the control group), while the second half of the sample underwent a treatment, which included also, along with the traditional psychosocial interventions, a psychoeducational treatment. Traditional treatment together with psychoeducation was able to reduce of $45 \%$ the number of hospitalization $[1,54]$.

In Italy a an open, controlled multicentric research was conducted in 15 Italian Community Mental Health Centers (Public Mental Health Departments and University Psychiatric Clinics), for the duration of 1 year, excluding the screening phases. In each CMHC, after each screening phase, the patients were blindly randomized by the experimenter into two groups. The control group (of a total of 66 people) was treated with a standard procedure (antipsychotic drug treatment and assertive community treatment), while the study group (69 patients) received, traditional psychosocial intervention, antipsychotic drug treatment and a psychoeducational program. Such sample, comprised of patients and their families, participated separately to 8 different parallel psychoeducational meetings, of 60-90 minutes each. Such meetings were characterized by an overlapping informative content, and were run by two psychiatric operators (mainly by a psychiatrist and a psychiatric nurse).

The scales assessment was carried out at the beginning of the trial, after 6 months (T2), and 12 months (T4). At the end of the study the parameters "Number of hospitalizations" and "Total number of hospital days" were checked. Each time drug recording and vital parameters were assessed. (Tab 1, Research protocol)

\subsection{Patients}

150 patients took part in this study. Their age ranged from 18 and 45 years. They were all diagnosed with schizophrenia, in agreement with the DSM IV (Diagnostic and Statistical Manual of Mental Disorders, fourth edition) and the ICD 10 (International Classification of Diseases, tenth

Table I: Research protocol

\begin{tabular}{ll}
\hline Time T-x & First screening phase \\
\hline Time T 0 & - Vital parameters \\
& - Analysis of the drug treatment characteristics and Drug treatment \\
& registration \\
Time T I (After 3 months) & - Assessment scales administration \\
Time T 2 (After 6 months) & - Vital parameters \\
& - Drug treatment registration \\
Time T 3 (After 9 months) & - Assessment scales administration \\
Time T 4 (After I months) & - Vital parameters \\
& - Vital parameters \\
& - Assessment scales administration \\
& - Control for the re-hospitalization rate (Number of hospitalizations,
\end{tabular}


edition) and were undergoing a standardized therapy in terms of types of drugs and dosages.

A set of criteria for the exclusion from the study included: acute psychosis, a substance abuse problem, organic factors that could interfere with the clinical condition, the patients' current participation in psychoeducational and structured treatments, or their participation in the last two years.

The analysis of the participants has shown no significant clinical and socio-demographic differences between the two groups. 135 patients finished the study; 15 dropped out for different reasons unrelated to the study.

\subsection{Antipsychotic drug treatment}

Both groups followed the antipsychotic drug treatment using traditional and atypical antipsychotic drugs, administered alone or combined. The current dosage was monitored every 6 months, from the beginning of the study. An equal percentage of patients in both the control and the study groups, received also, during the study, some depot or "long acting" (haloperidol decanoate, fluphenazine decanoate, zuclopentixol decanoate) anti-psychotic drugs.

\subsection{Psychiatric assessment Scales}

The following scales were administered during the study: BPRS (Brief Psychiatric Rating Scale), SAPS (Scale for Assessment of Positive Symptoms), SANS (Scale for Assessment of Negative Symptoms), Sympson and Angus Scale, ROMI (Rating of Medication Influences) and the Lancaster QL (Lancaster Quality of Life Profile).

\subsection{Psychoeducational program}

The standardized psychoeducational program, managed through an interactive educational method, took place in 8 sessions, in which the following topics were covered:

1. Introduction

2. What is schizophrenia?

3. What causes schizophrenia?

4. How to treat schizophrenia?

5. Psychosocial treatment strategies

6. Preventing relapses

7. The role of the family

8. Conclusion

\subsection{Statistical methods}

All of the data was elaborated and statistically measured using the SAS procedure $v$ 6.12. The basal homogeneity of the groups was measured for both the demographic characteristics and the measuring scales, using the Wilcoxon's non-parametric test.

The measurement within treatments was conducted taking in consideration the starting and ending time of the treatment: the significance of the difference was measured using the Sign Rank Test.

The treatments were compared using an ANOVA model, in which the fixed effects were the treatment and the centers; the assessment of the differences was done on the LS means (means calculated with the least squares' method) using the LSD test of the PRCO GLM.

\subsection{Consent}

The study was approved by the ethical committee and the patient gave written informed consent.

\section{Results}

\section{I Socio demographic and clinical parameters}

The two subgroups of subjects participating in the test have the same clinical and socio-demographic characteristics. The percentage of male vs female and the age groups stratification in both groups appears to be similar, and the differences are not of statistical significance. (Fig 1, Age ; Fig 2, Sex)

Heart rate, blood pressure and body weight measurements have remained the same during the entire treatment program. (Tab. 2, Vital parameters)

Diagnosis according to the DSM IV has brought to a further subdivision of the different subtypes of schizophrenia, the main one being the paranoid type, respectively

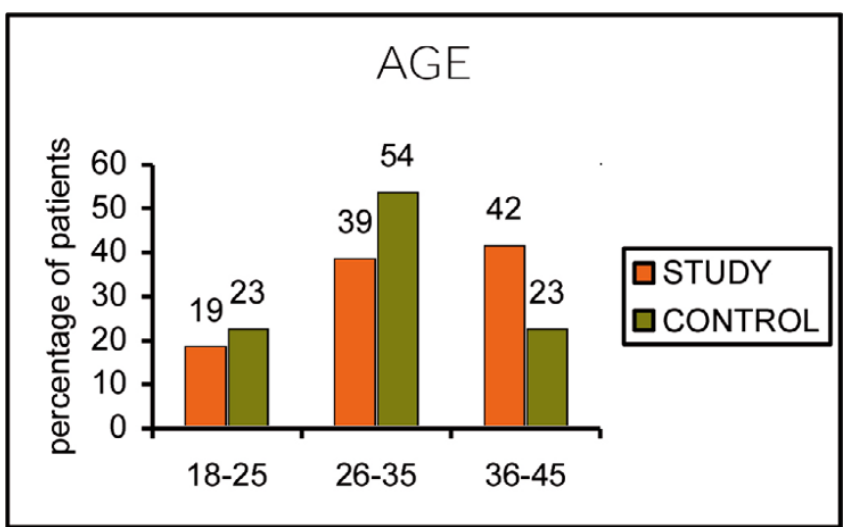

Figure I

Age. 


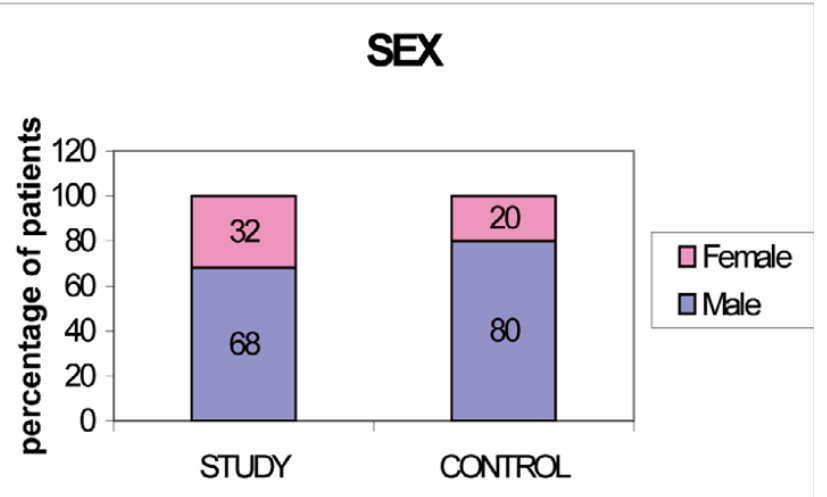

Figure 2

Sex.

$40 \%$ in the study group and $43 \%$ in the control group (difference n.s.). (Tab. 3, Diagnosis)

Time from the first diagnosis, the years of treatment, the number of hospitalizations, and the current psychopharmacological treatment, were also kept under consideration.

All of the parameters have resulted substantially homogeneous and there was no substantial statistical significance between the two study groups. (Tab. 4, Clinical parameters: years from the diagnosis, years of treatment, number of hospitalizations)

\subsection{Assessment Scales}

The BPRS showed a decrease in the gravity of symptoms for both groups, but while the control group varied from a basic score of 58.27 to a score of 47.45 after 12 months with an improvement of 10.82 points $(\mathrm{p}<0.05)$. The study group showed a score of 56.77 at T0 and of 40.23 at
T4 with 16.54 points of difference ( $\mathrm{p}<0.05)$. The difference between the groups was statistically significant in favor to the study group. ( $\mathrm{p}<0.05)$. (Fig. 3, BPRS scale)

The detailed analysis of the single items of the BPRS scale, allows to highlight the items that changed most. The study group has shown a better improvement $(\mathrm{p}<0.05)$ in delayed

emotional flattening, anxiety, emotional withdrawal, distractibility, thought disorganization, lack of collaboration, artificial attitude. The motor skill and the excitability items decreased equally in both groups $(p>0.05)$ (Tab. 5, BPRS scale: assessment of item "emotion").

The study group had a significant improvement $(\mathrm{p}<0.05)$ in items of the BPRS Behaviour subscale such as: depression, personal neglect, somatic preoccupation, and unusual thought process. (Tab. 6, BPRS scale: assessment of item: "behavior")

SAPS Scale was used to asses positive symptoms (hallucinations, delusions, strange behavior, thought disorder). The total score has shown a statistical significant decrease for both groups. The study group changed from 47.2 to 32.57 points with a difference of 15.7 points $(<0.05)$; the control group varied from 48.46 to 41.71 points with a 6.75 point difference. A highly significant difference was found between the two groups $(<0.001)$. (Fig. 4, SAPS scale)

A reduction in the delusional symptoms has contributed to a significant difference of 8.19 points compared with 4.74 points for the control group ( $\mathrm{p}<0.01$ ). (Fig. 5, SAPS scale, group of items)

The analysis of the changes in the negative symptoms was conducted using the SANS Scale. The study group showed an improvement of 9.9 points (from 56.63, to 46.73

Table 2: Vital parameters

\begin{tabular}{|c|c|c|c|c|c|}
\hline$(p>0.05)$ VITAL PARAMETERS & TO & $\mathrm{TI}$ & $\mathrm{T} 2$ & $\mathrm{~T} 3$ & T4 \\
\hline \multicolumn{6}{|l|}{ Heart rate (Beats/min) } \\
\hline STUDY & 81,92 & 80,58 & 81,80 & 80,55 & 80,97 \\
\hline CONTROL & 79,92 & 78,82 & 80,02 & 80,64 & 82,16 \\
\hline \multicolumn{6}{|l|}{ Systolic pressure $(\mathrm{mmHg})$} \\
\hline STUDY & 119,90 & 118,72 & 120,43 & 121,97 & 121,50 \\
\hline CONTROL & 121,35 & 120,54 & $|2|, 9 \mid$ & 120,33 & 122,97 \\
\hline \multicolumn{6}{|l|}{ Diastolic pressure $(\mathrm{mmHg})$} \\
\hline STUDY & 75,73 & 75,09 & 75,33 & 75,97 & 76,33 \\
\hline CONTROL & 75,63 & 75,74 & 75,53 & 74,66 & 77,33 \\
\hline \multicolumn{6}{|l|}{ Body weight $(\mathrm{Kg})$} \\
\hline STUDY & 76,04 & 76,52 & 76,78 & 77,26 & 75,90 \\
\hline CONTROL & 76,98 & 77,70 & 76,63 & 78,01 & 79,65 \\
\hline
\end{tabular}


Table 3: Diagnosis

\begin{tabular}{lll}
\hline DIAGNOSIS & STUDY (\%) & CONTROL (\%) \\
\hline Schizophrenia & 15 & 17 \\
Disorganized Schizophrenia & 9 & 23 \\
Paranoid Schizophrenia & 40 & 43 \\
Catatonic Schizophrenia & 2 & 0 \\
Non-differentiated Schizophrenia & 19 & 13 \\
Residual Schizophrenia & 15 & 4 \\
\hline
\end{tabular}

points, $\mathrm{p}<0.05)$ while the control group had and improvement of only 0.66 points, going from 52.8 to 51.52. (n.s). The difference between the groups had statistical significance $(\mathrm{p}<0.05)$ (Fig. 6, SANS scale).

The study group showed a significant difference in the item distraction, showing a change of 1.62 points compared to the 0.81 points of change for the control group ( $p<0.05)$. As for the other parameters, the study group scored better improvements, but the difference between the groups was non significant ( $\mathrm{p}>0.05)$. (Fig 7 , SANS scale, group of items)

The ROMI Scale measures the reasons for participating or not in a treatment program and was assessed by both the patients and the research physicians.

The subset "Reasons for good participating to the treatment", showed no difference between the groups ( $\mathrm{p}>$ 0.05). (Fig 8, ROMI scale: reasons for participating)

The subset "Reasons for non participating to the treatment" such as bad relationship between the doctor and the patient, bad relationship with the psychiatric staff, denial about the disease, need for current treatment, desire for hospitalization, interference with personal activities, refusal to take medications, were improved in the control group with and increase of 0.08 points compared to a decrease of 1.8 points for the study group ( $\mathrm{p}<$ 0.05). (Fig 9, ROMI scale: reasons for non participating)

The Simpson-Angus Scale measures the assessment of the extrapyramidal effects. Though the different treatments were comparable between the two groups, the study group showed a decrease of 1.36 points compared with 0.97 points for the control group but the difference was non significant. $(\mathrm{p}>0.05)$. (Fig. 10, Simpson-Angus scale)

The quality of life at the Lancashire QL scale demonstrated ad increase for the study group of 9.52 points (from 100,85 points, to 110,37 points), and an improvement for the control group of 0.33 points for the total scale $(\mathrm{p}<$ $0.05)$; in particular regard to the items wellness, work, leisure, religion, economic situation, family relationship, social relationship, overall wellbeing ( $\mathrm{p}<0.05)$. (Fig 11, Lancashire QL scale)

The percentage of the subjects hospitalized between 1 and 3 times during the 12 months resulted to be $13 \%$ after 6 months, and 3,3\% after a year with a difference of $9.7 \%$ for the study group; while for the control group the variation went from $17.7 \%$ at 6 months to $10.5 \%$ after 1 year with an improvement of $7,2 \%$. The difference between

Table 4: Clinical parameters: years from the diagnosis, years of treatment, number of hospitalizations

\begin{tabular}{|c|c|c|c|}
\hline Clinical parameters & Duration & STUDY (\%) & CONTROL (\%) \\
\hline \multirow[t]{4}{*}{ Number of years from the diagnosis of schizophrenia } & Less than I year & 2 & 4 \\
\hline & From I to 5 years & 31 & 55 \\
\hline & From 6 to 10 years & 37 & 19 \\
\hline & Over 10 years & 30 & 22 \\
\hline \multirow[t]{4}{*}{ Number of years of treatment } & Less than I year & 5 & 5 \\
\hline & From I to 5 years & 36 & 56 \\
\hline & From 6 to 10 years & 34 & 19 \\
\hline & Over 10 years & 25 & 20 \\
\hline \multirow[t]{5}{*}{ Number of hospitalizations in the last three years } & None & 28 & 26 \\
\hline & From I to 3 & 48 & 47 \\
\hline & From 4 to 6 & 18 & 19 \\
\hline & From 7 to 10 & 2 & 6 \\
\hline & Over 10 & 4 & 2 \\
\hline
\end{tabular}




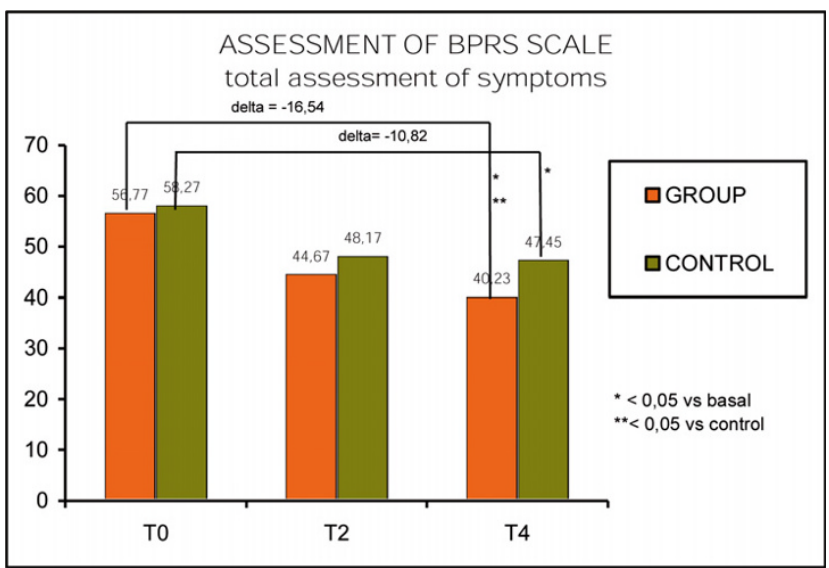

Figure 3

BPRS scale.

groups showed statistical significance ( $\mathrm{p}<0.05)$. (Fig. 12, Number of Hospitalizations)

There was also a decrease of mean number of days of hospital stays for each hospitalisationfor the study group (42 days) compared to the control group (53 days); ( $\mathrm{p}<$ 0.05). (Fig. 13, Number of days of hospital stays)

\section{Discussion}

\section{I Findings}

The experimental group showed a significant statistical improvement $(\mathrm{p}<0,05)$ in almost all the scales that have been assessed (BPRS, SAPS, SANS, SIMPSON-ANGUS SCALE, LANCASHIRE QL SCALE). Significant was the reduction of relapse in terms of numbers of hospitalization, days of hospital stay and clinical parameters. This was the main objective of our study and was significantly confirmed in the effect of the overall improvent on most clinical parameters, quality of life, relation with the staff.

The different changing in BPRS over the time can suggest the role of psychoeducation in the improvement of clinical parameters. Both groups showed a decrease of gravity of the symptoms in the first 4 months, this can be due to the consolidated synergy between drug treatment and standard psychosocial intervention. The study group keeps on improving over the 12 months of the study and this can be related to the capacity of psychoeducation to help in handling with the symptoms, have a better therapeutic alliance and prevent the relapse of the psychosis. The analysis of BPRS can show how much psychoeducation can help in reduce certain symptoms as emotional flattening, anxiety, emotional withdrawal, distractibility, thought disorganization, lack of collaboration, artificial attitude, but especially we found a particular improvement in depression, personal neglect, somatic preoccupation, and unusual thought process.

To a less extent psychoeducation can improve anxiety, confusion, hallucinations, strange behavior, over excitement, grandiose feelings, hostility, suicidal tendencies. As for the suspicion item, the difference was identical for both groups: a more specific treatment can be required to improve this item.

The changing in both positive and negative symptoms measured by SAPS and SANS scales evidences how psychoeducation can give a generalized improvement over all kind of symptoms.

The changes in ROMI scale highlighted the importance of psychoeducation as shown by the improvement of the relationship with the staff, the increase of awareness of the

Table 5: BPRS scale: assessment of item "emotion"

\begin{tabular}{|c|c|c|c|c|c|c|}
\hline \multicolumn{7}{|c|}{ THE BPRS SCALE Assessment of each item: EMOTION } \\
\hline & \multicolumn{3}{|c|}{ GROUP } & \multicolumn{3}{|c|}{ CONTOL } \\
\hline & TO & $\mathrm{T} 4$ & Diff. & TO & $\mathrm{T} 4$ & Diff, \\
\hline Thought disorganization & 2,56 & 2,00 & $-0,56$ & 2,34 & 2,18 & $-0,16$ \\
\hline Emotional flattening & 3,24 & 2,24 & $-7,00$ & 2,80 & 2,61 & $-0,79$ \\
\hline Emotional withdrawal & 3,37 & 2,34 & $-7,03$ & 3,18 & 2,80 & $-0,38$ \\
\hline Delayed motor skills & 2,53 & 1,42 & $-1,11$ & 2,13 & 1,85 & $-0,28$ \\
\hline Tension & 3,48 & 2,16 & -1.32 & 3,10 & 2,55 & $-0,55$ \\
\hline Lack of compliance & 2,11 & 1,29 & $-0,82$ & 1,98 & 1,56 & $-0,42$ \\
\hline Excitement & 1,63 & 1,11 & $-0,52$ & 1,99 & 1,44 & $-0,55$ \\
\hline Distractibility & 2,38 & 1,40 & -0.98 & 2,30 & 1,80 & $-0,50$ \\
\hline Motor skill hyperactivity & 1,59 & 1,06 & $-0,53$ & 1,76 & 1,32 & $-0,44$ \\
\hline Artificial behavior & 1,89 & 1,24 & $-0,65$ & 1,92 & 1,67 & $-0,25$ \\
\hline TOTAL Assessment & 24,80 & 16,27 & $-8,53$ & 23,47 & 19,77 & $-3,70$ \\
\hline
\end{tabular}


Table 6: BPRS scale: assessment of item: "behaviour"

BPRS SCALE Assessment of each item: BEHAVIOUR

\begin{tabular}{|c|c|c|c|c|c|c|}
\hline & GROUP & & & $\mathrm{CON}$ & & \\
\hline & TO & $\mathrm{T} 4$ & Diff, & T0 & $\mathrm{T} 4$ & Diff. \\
\hline $\begin{array}{l}\text { Somatic } \\
\text { preoccupation }\end{array}$ & 3,23 & 2,08 & $-1,15$ & 2,77 & 2,23 & $-0,54$ \\
\hline Anxiety & 3,59 & 2,40 & $-1,19$ & 3,25 & 2,47 & $-0,78$ \\
\hline Depression & 2,71 & 1,53 & $-1,18$ & 2,52 & 2,08 & $-0,44$ \\
\hline Suicidal tendencies & 1,01 & 0,85 & -0.16 & 1,11 & 1,03 & $-0,08$ \\
\hline Feelings of guilt & 2,03 & $|, 2|$ & $-0,82$ & $|, 7|$ & 1,60 & $-0,11$ \\
\hline Hostility & 2,17 & 1,32 & $-0,85$ & 2,48 & 1,73 & $-0,75$ \\
\hline Over excitement & $|, 6|$ & 1.06 & $-0,55$ & 1,76 & 1,36 & $-0,40$ \\
\hline Grandiosity & 1,99 & 1,26 & $-0,73$ & 2,18 & 1,59 & $-0,59$ \\
\hline $\begin{array}{l}\text { Suspicious } \\
\text { behavior }\end{array}$ & 2,94 & 1,76 & $-0,18$ & 3,67 & 2,48 & $-0,19$ \\
\hline Hallucinations & 2,50 & 1,58 & $-0,92$ & 2,55 & 1,91 & $-0,64$ \\
\hline $\begin{array}{l}\text { Unusual thought } \\
\text { process }\end{array}$ & 3,59 & 2,27 & $-1,32$ & 3.23 & 2,45 & $-0,78$ \\
\hline Strange behavior & 2,50 & I,7! & $-0,79$ & 2,72 & 2,08 & $-0,64$ \\
\hline Personal neglect & 2,48 & 1,53 & $-0,95$ & 2,32 & 2,09 & $-0,23$ \\
\hline Disorientation & I,47 & 1,00 & $-0,47$ & 1,13 & 1,27 & 0,74 \\
\hline $\begin{array}{l}\text { TOTAL } \\
\text { Assessment }\end{array}$ & 33,82 & 21,56 & $-12,26$ & 33,26 & 26,24 & $-7,02$ \\
\hline
\end{tabular}

illness and the needing for treatment, the positive believe of the family, the prevention of relapse and the improvement of compliance. The psychoeducational approach has helped family members to live with patients and their disorder, and, at the same time, it has highlighted the more positive qualities of patients.

The lack of significant difference in the extrapiramidal effect (Simpson-Angus scale) can be explained with the

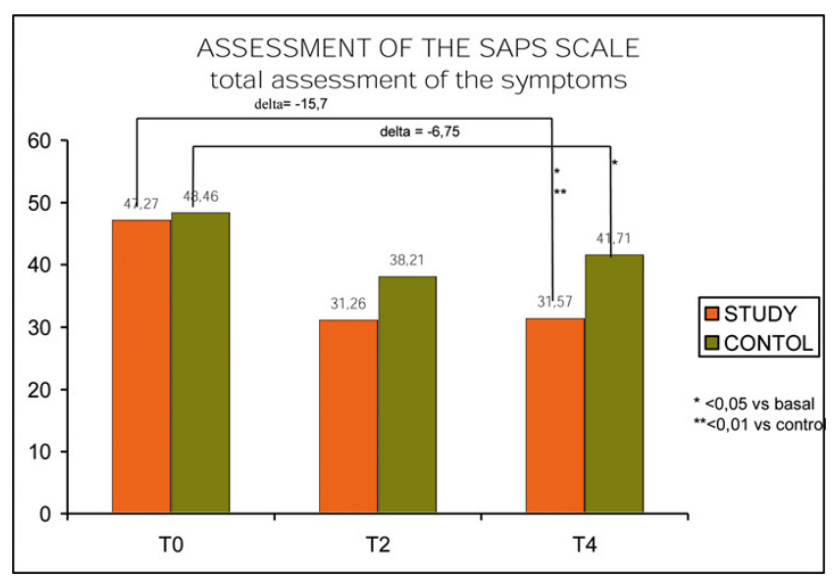

Figure 4

SAPS scale. consideration the this parameter is due to the pharmacotherapy and it is not significantly influenced by psychoeducation, though the difference registered between the two groups can show that psychoeducation can teach the patient and the family to recognize earlier the side effects and relate to the doctor for changing the drug treatment.

The study group has shown an important and persistent improvement in the quality of life (Lancashire scale), while the other group had not improved over the year of

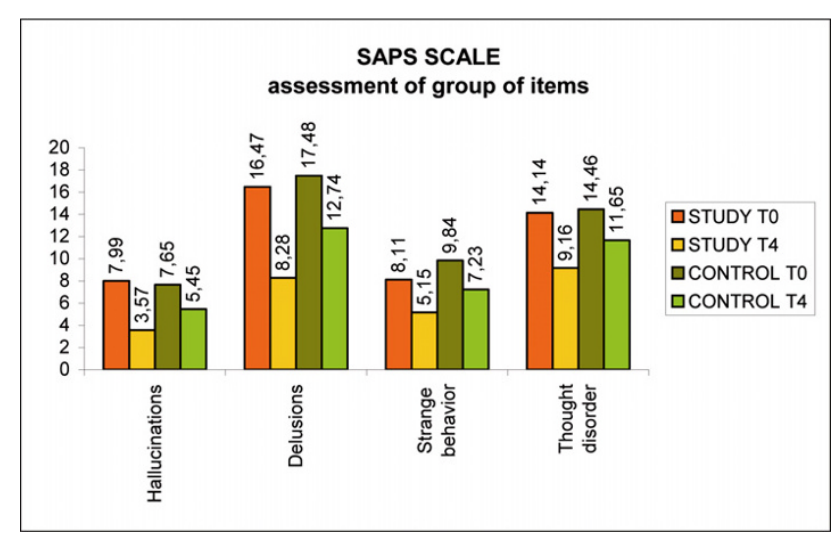

Figure 5

SAPS scale, group of items. 


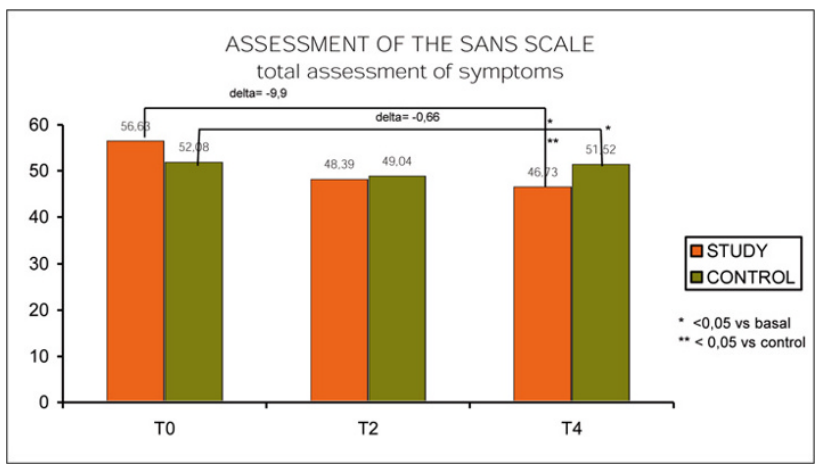

Figure 6

SANS scale.

the study: this difference in due to the overall benefits of psychoeducation that lead to a better adherence to the whole program.

The number of psychoeducational sessions was only 8 and we suggest this program could be further improved in terms of number of sessions, items of discussions, role of the family and the patients in the process in order to better maintain the positive outcomes and the parameters that have not improved.

\subsection{Methodological issues}

This study has some limitations. It is a cross-sectional study and cohort effect can distort the results. The number of the patients in small, so larger studies is needed to confirm this data. This bias could be reduced comparing the data with an international meta-analysis.

Though the staff carrying out psychoeducation and standard psychosocial intervention and the staff administering

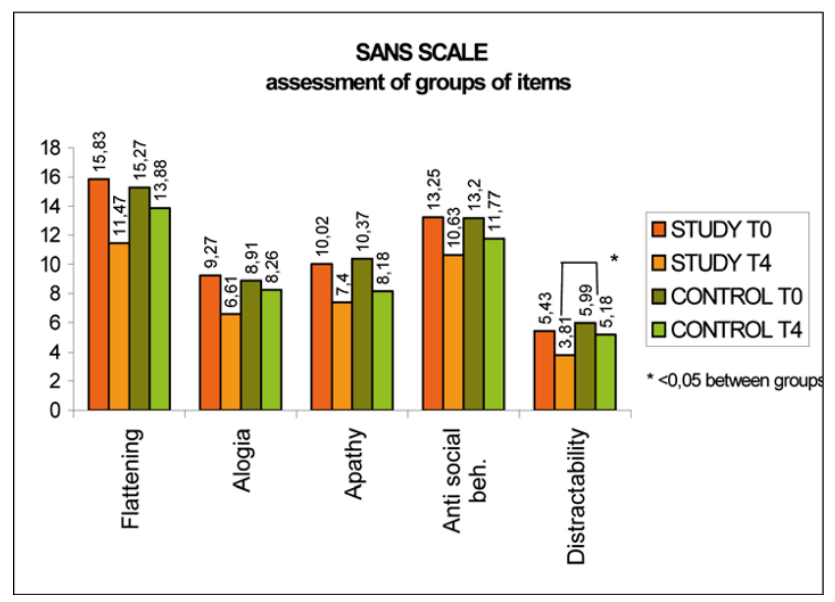

Figure 7

SANS scale, group of items.

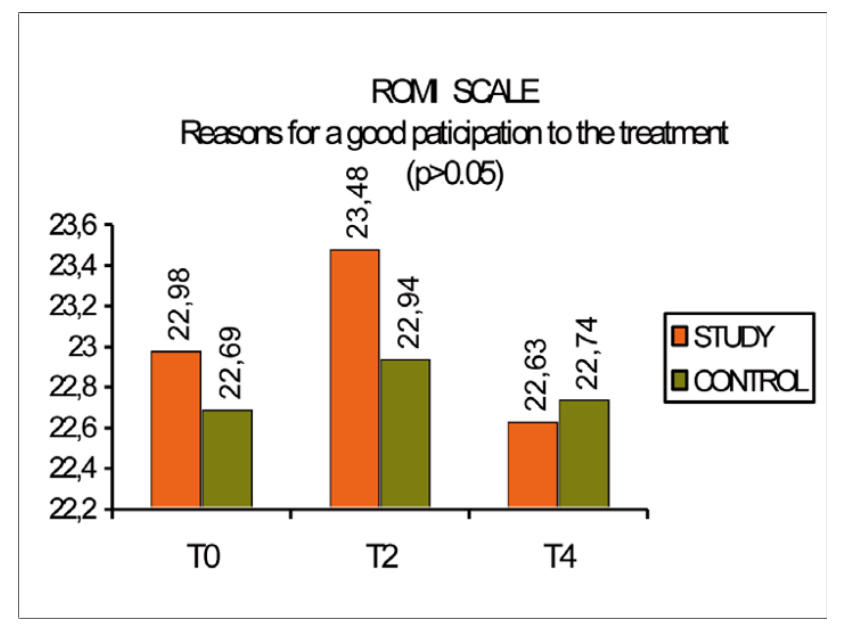

Figure 8

ROMI scale: reasons for participating.

the scales were different, the open label design of the study could bring some biases. A double blind study should be recommended.

This study has several strengths. It evaluates the efficacy of psychoeducation in the real clinical practice following a multicenter design and it analyses not only the clinical parameters, the relationship and the quality of life as different parameters, but it also focuses on how the improvement of compliance can lead to a reduction of relapse, as it is shown in international literature.

\section{Conclusion}

A number of studies have show that a psychoeducational intervention with schizophrenic patients and their families, could reduce the occurrence of relapse [2,55-58].

Such decrease seems to be related with a decrease in hospitalizations, with less sick days on the job, and with less social expenses [59-61].

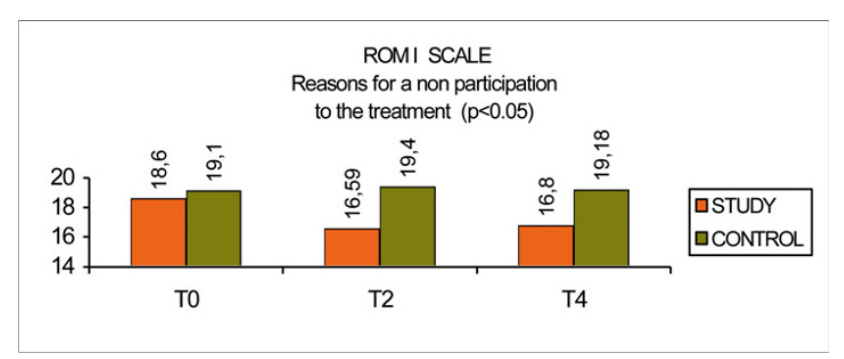

Figure 9

ROMI scale: reasons for non participating. 


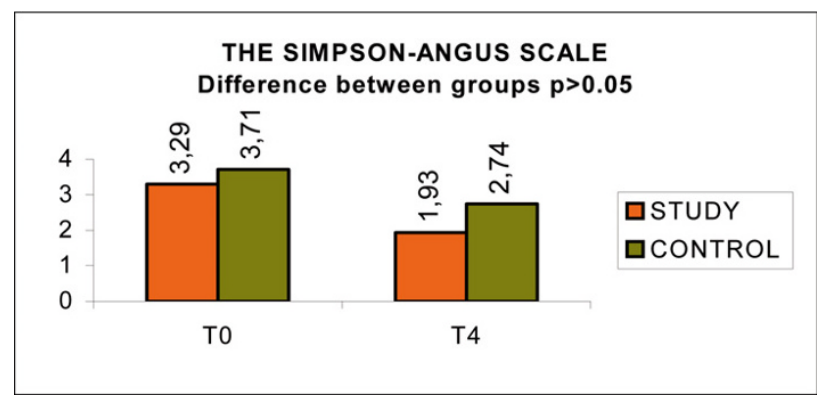

Figure 10

Simpson-Angus scale.

The study is part of an international program whose effort is to assess the effectiveness of a psychoeducational treatment in the prevention of relapses, through a change in the understanding and the acceptance of the disorder. Our study confirms improvements on most clinical parameters, quality of life, adherence to the treatment program, reduction of relapse and number of hospitalisation.

A psychoeducational therapeutic approach always seems to have positive effects on both the patients and their family. In fact, results show that even short term educationalinformative contents were able to improve the patients' level of compliance to the treatment program, the patients' and their family members' attitude toward the disorder, and their attitude toward the psychiatric staff. Also, such educational approach seem to be able to improve the individuals' perception of quality of life, which represents an indirect tool used to reduce self and hetero-stigmatization. The participation of family members in the study has allowed a more effective management of the patient and a better implementation of a psychosocial rehabilitation process.

In addition to the unquestionable advantages of such integrative treatment plan, there is also a decrease in costs

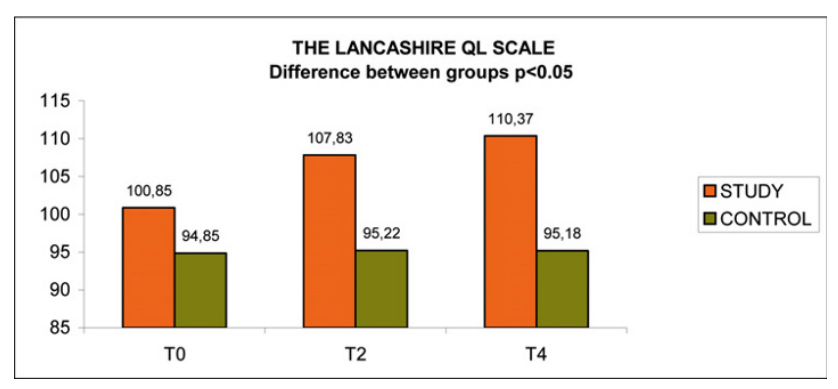

Figure I I

Lancashire QL scale.

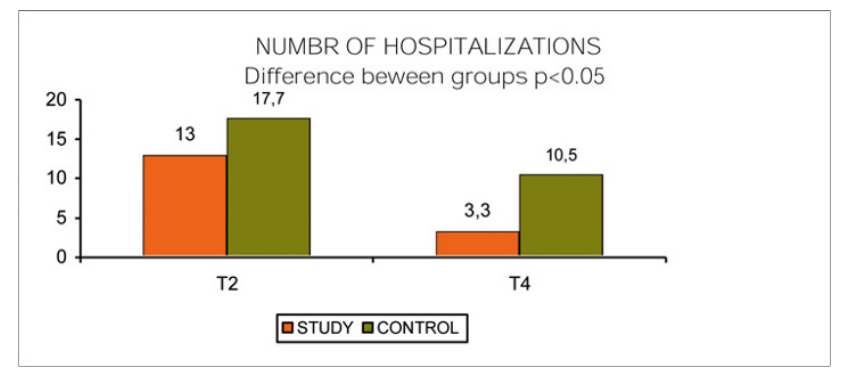

Figure 12

Number of Hospitalizations.

associated with hospitalizations, loss of working days, tension, family and social apprehensions.

In conclusion, such multicentric experience allows us to confirm that the psychoeducational approach has contributed significantly to an integrated approach that put together patients active role in managing symptoms, family members participation and psychiatric staff work that led to a global improvement and a reduction of relapses and hospitalizations.

The result is an undoubtedly great advantage for the patients, who becomes an active participant in their therapeutic process, experiencing not only an improvement from a clinical stand point, but also an overall increased psychological wellness, reducing significantly the troubles and the bad feelings caused by such afflicting disorder.

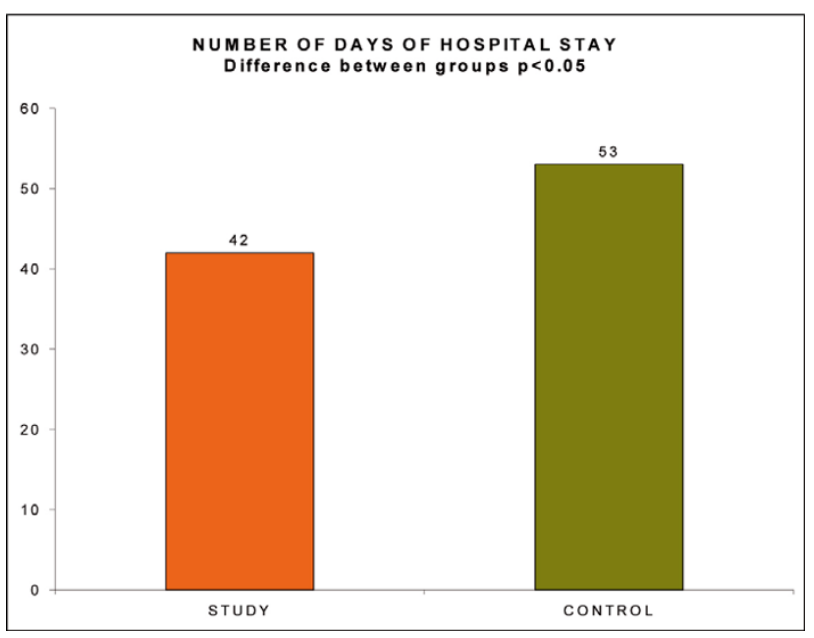

Figure 13

Number of days of hospital stays. 


\section{Competing interests}

The author(s) declare that they have no competing interests.

\section{Acknowledgements \\ Mazzaglia Giampiero.}

\section{References}

I. Sherman MD: Updates and five-year evaluation of the S.A.F.E. program: A family psychoeducational program for serious mental illness. Community Mental Health J 2006, 42:213-219.

2. Falloon IRH, Roncone R, Held T, Coverdale JH, Laidlaw TM: An international overview of family interventions. In Family interventions in mental illness: International perspectives Edited by: Lefley HP, Johnson DL. Westport, CT: Praeger; 2002.

3. Falloon IRH, Montero I, Sungur M, Mastroeni A, Malm U, Economou M, Grawe R, Harangozo J, Mizuno M, Murakami M, Hager B, Held T, Veltro F, Gedye R, The Otp Collaborative Group: Implementation of evidence-based treatment for schizophrenic disorders: two-year outcome of an international field trial of optimal treatment. World Psychiatry 2004, 3(I): I04-109.

4. Bustillo J, Lauriello J, Horan W, Keith S: The psychosocial treatment of schizophrenia: an update. Am J Psychiatry 200I, 158:163-75.

5. National Institute for Clinical Excellence: Clinical Guideline I: Schizophrenia. Core interventions in the treatment and management of schizophrenia in primary and secondary care London: NICE; 2002.

6. Thornicroft G, Susser E: Evidence-based psychotherapeutic interventions in the community care of schizophrenia. $\mathrm{Br} J$ Psychiatry 200I, 178:2-4.

7. Motlova L: Psychoeducation as an indispensable complement to pharmacotherapy in schizophrenia. Pharmacopsychiatry 2000, 33(Suppl I):47-8.

8. American Psychiatric Association: Practice guideline for treatment of patients with schizophrenia. Am J Psychiatry 1997, 154(Suppl 4):.

9. Falloon IRH and The Optimal Treatment Project Collaborators: Optimal treatment for psychosis in an international multisite demonstration project. Psychiatr Serv 1999, 50:615-8.

10. Lehman AF, Steinwachs DM: Patterns of usual care for schizophrenia. Initial results from the Schizophrenia Patient Outcomes Research Team (PORT) client survey. Schizophr Bull 1998, 24:II-20.

II. Falloon IRH, Held T, Roncone R, Coverdale JH, Laidlaw TM: Optimal treatment strategies to enhance recovery from schizophrenia. Aust N Z J Psychiatry 1998, 32(I):43-9.

12. Dixon L, Adams C, Lucksted A: Update on family psychoeducation for schizophrenia. Schizophr Bull 2000, 26(I):5-20.

13. Lehman AF, Steinwachs DM: At issue: Translating research into practice: The schizophrenia patient outcomes research team (PORT) treatment recommendations. Schizophrenia Bulletin 1998, 24(I): I- I0.

14. Penn DL, Mueser KT: Research update on the psychosocial treatment of schizophrenia. Am J Psych 1996, I53:607-6I7.

15. Buchkremer G, Klingberg S, Holle R, Schulze Mönking H: Psychoeducational psychotherapy for schizophrenic patients and their key relatives or care givers. Results of a 2-year follow-up. Acta Psychiatr Scand 1997, 96:483-49I.

16. Sherman MD: The Support and Family Education (SAFE) program: mental health facts for families. Psychiatr Serv 2003, 54(I):35-37.

17. Pekkala E, Merinder L: Psychoeducation for schizophrenia. Cochrane Database Syst Rev 2002:CD00283I.

18. McFarlane WR, Dixon L, Lukens E, Lucksted A: Family psychoeducation and schizophrenia: a review of the literature. I Marital Fam Ther 2003, 29(2):223-45.

19. Falloon IHR, Coverdale JH, Brooker C: Psychosocial interventions in schizophrenia: a review. International Journal of Mental Health 1996, 25:3-21.

20. Casacchia M, Roncone R: I trattamenti psicoeducativi familiari nella schizofrenia: esterofilia o applicazione di interventi basati sull'evidenza? Epidemiologia e Psichiatria Sociale 1999, 8(3): 183-189.
21. Lam DH: Psychosocial family intervention in schizophrenia: a review of empirical studies. Psychological Medicine 1991, $21: 423-441$.

22. Mari J], Streiner D: An overview of family interventions and relapse on schizophrenia: meta - analysis on research findings. Psychological Medicine 1994, 24(3):565-578.

23. Dixon LB, Lehman AF: Family interventions for schizophrenia. Schizophrenia Bulletin 1995, 2 I (4):63 I-643.

24. Mari J], Adams CE, Streiner D: Family intervention for those with schizophrenia. In Schizophrenia Module of the Cochrane Database Systematic Reviews Issue 3 Edited by: Adams CE, Anderson J, De Jesus J, Mari J. Cochrane Library(CDROM), Update Software, Oxford; 1997.

25. Casacchia M, Roncone R: Trattamenti psicosociali familiari. In Trattato Italiano di Psichiatria Masson, Milano. Cassano GB e coll; 1999:3675-37|2.

26. Pitschel-Walz G, Leucht S, Bauml J, Kissling W, Engel RR: The effect of family interventions on relapse and rehospitalization in schizophrenia: a meta - analisys. Schizophrenia Bulletin 200I, 27(I):73-92.

27. Boczkowski JA, Zeichner A, DeSanto N: Neuroleptic compliance among chronic schizophrenic outpatients: an intervention outcome report. Journal of Consulting and clinical psychology 1985, 53:666-67।.

28. Pekkala E, Merinder L: Psychoeducation for schizophrenia. The Cochrane Database of Systematic Reviews 2006.

29. Brown CS, Wright RG, Christensen DB: Association between type of medication instruction and patients' knowledge, side effects and compliance. Hospital and Community Psychiatry 1987, 38(I):55-60.

30. Zygmunt A, Olfson M, Boyer C, Mechanic D: Interventions to Improve Medication Adherence in Schizophrenia. Am J Psychiatry 2002, I59:1653-1664.

31. Dyck DG, Hendryx MS, Short RA, Voss WD, McFarlane WR: Service use among patients with schizophrenia in psychoeducational multiple-family group treatment. Psychiatric Services 2002, 53(6):749-754.

32. Dyck DG, Short RA, Hendryx MS, Norell D, Myers M: Management of negative symptoms among patients with schizophrenia attending multiple-family groups. Psychiatric Services 2000, $51(4): 513-519$

33. Herz MI, Lamberti JS, Mintz J, Scott R, O'Dell SP, McCartan L, Nix G: A program for relapse prevention in schizophrenia: a controlled study. Arch Gen Psychiatry 2000, 57(3):277-283.

34. Fenton WS, Blyler C, Heinssen RK: Determinants compliance in schizophrenia: empirical and clinical findings. Schizophr Bull 1997, 23:637-65।.

35. Babiker IE: Noncompliance in schizophrenia. Psychiatr Dev 1986 , 4:329-337.

36. Weiden PJ, Olfson M: Cost of relapse in schizophrenia. Schizophr Bull 1995, 21:419-42.

37. Yamada K, Watanabe K, Nemoto N, Fujita H, Chikaraishi C, Yamauchi K, Yagi G, Asai M, Kanba S: Prediction of medication noncompliance in outpatients with schizophrenia: 2-year follow-up study. Psychiatry Res 2006, 30; I4I(I):6I-9.

38. Vauth R, Loschmann C, Rusch N, Corrigan PW: Understanding adherence to neuroleptic treatment in schizophrenia. Psychiatry Research 2004, I 26:43-49.

39. Weiden PJ, Shaw E, Mann J: Antipsychotic therapy: patient preferences and compliance. Curr Appr Psychosis 1995, 4: I-7.

40. Fleischhacker WW, Meise U, Gunther V, Kurz M: Compliance with antipsychotic drug treatment: influence of side effects. Acta Psychiatr Scand 1994, 89: I I-15.

41. Buchanan A: A two year prospective study of treatment compliance in patient with schizophrenia. Psychol Med 1992, 22:787-797.

42. Eaddy M, Grogg A, Locldear J: Assessment of Compliance with antipsychotic Treatment and Resource Utilization in a Medicaid Population. Clinical Therapeutics 2005, 27(2):263-272.

43. Weiden P, Kozma C, Grogg A, Locklear J: Partial compliance and risk of rehospitalization among California Medicaid patients with schizophrenia. PsychiatrServ 2004, 55(8):886-891.

44. Buchkremer G, Klingberg S, Holle R, Schulze Mönking H, Hornung WP: Psychoeducational psychotherapy for schizophrenic patients and their key relatives or care givers. Results of a 2 year follow-up. Acta Psychiatr Scand 1997, 96:483-491. 
45. Pollio DE, North CS, Reid DL, Miletic MM, McClendon JR: Living with severe mental illness - what families and friends must know: evaluation of a one-day psychoeducation workshop. Soc Work 2006, 5 I (I):3 I-8.

46. Brown CS, Wright RG, Christensen DB: Association between type of medication instruction and patients' knowledge, side effects and compliance. Hospital and Community Psychiatry 1987, 38:55-60.

47. Mcpherson R, Jerrom B, Hughes A: A controlled study of education about drug treatment in schizophrenia. British Journal of Psychiatry 1996, 168:709-717.

48. Pollio DE, North CS, Osborne VA: Family-Responsive Psychoeducation Groups for Families with an Adult Member with Mental IIlness: Pilot Results. Community Mental Health Journal 2002, 38(5):499-509.

49. Nelson A: Drug default among schizophrenic patients. Am Jl of Hospital Pharmacy 1975, 32(12): $1237-1242$.

50. Strang JS, Falloon IRH, Moss HB, Razani J, Boyd JL: The effects of family therapy on treatment compliance in schizophrenia. Psychopharmacology Bulletin 198I, I 7(3):87-88.

5I. Falloon IRH: Developing and maintaining adherence to long term drug tacking regimens. Schizophrenia Bulletin 1984, I0(3):4|2-4|7.

52. Eckman TA, Liberman RP, Phipps CC, Blair KE: Teaching medication management skills to schizophrenic patients. Journal of Clinical Psychopharmacology 1990, I0(I):33-38.

53. Kelly GR, Scott JE: Medication compliance and health education among outpatients with chronic mental disorders. Medical Care 1990, 28: I I8I-I I97.

54. Pitschel-Walz G, Bauml J, Bender W, Engel RR, Wagner M, Kissling $\mathrm{W}$ : Psychoeducation and compliance in the treatment of schizophrenia: results of the Munich Psychosis Information Project Study. J Clin Psychiatry 2006, 67(3):443-52.

55. Hogarty GE, Anderson CM, Reiss DJ, Kornblith SJ, Greenwald DP, Ulrich RF, Carter M: Family psychoeducation, social skills training, and maintenance chemotherapy in the aftercare treatment of schizophrenia. II. Two-year effects of a controlled study on relapse and adjustment. Environmental-Personal Indicators in the Course of Schizophrenia (EPICS) Research Group. Arch Gen Psych I99I, 48(4):340-347.

56. Mingyuan Z, Heqin $Y$, Chengde $Y$, Jianlin $Y$, Qingfeng $Y$, Peijun $C$, Lianfang G, Jizhong $Y$, Guangya $Q$, Zhen W, Jianhua C, Minghua S, Jushan H, Longlin W, Yi Z, Buoying Z, Orley J, Gittelman M: Effectiveness of psychoeducation of relatives of schizophrenic patients: a prospective cohort study in five cities of China. International Journal of Mental Health 1993, 22:47-59.

57. Xiong W, Phillips MR, Hu X, Wang R, Dai Q, Kleinman J, Kleinman A: A family-based intervention for schizophrenic patients in China: a randomized controlled trial. British Journal of Psychiatry 1994, 165:239-247.

58. Rund BR, Moe L, Sollien T, Fjell A, Borchgrevink T, Hallert M, Naess PO: The psychosis project: outcome and cost-effectiveness of a psychoeducational treatment program for schizophrenic adolescents. Acta Psychiatrica Scandinavica 1994, 89:2 II-2I8.

59. Dyck DG, Hendryx MS, Short RA, Voss WD, McFarlane WR: Service use among patients with schizophrenia in psychoeducational multiple-family group treatment. Psychiatric Services 2002, 53(6):749-754.

60. Herz MI, Lambert JS, Mintz J, Scott R, O'Dell SP, McCartan L, Nix G: A program for relapse prevention in schizophrenia: a controlled study. Archives of General Psychiatry 2000, 57(3):277-83.

61. Hahlweg K, Wiedemann G: Principles and results of family therapy in schizophrenia. Eur Arch Psychiatry Clin Neurosci 1999, 249(Suppl 4): 108-115.

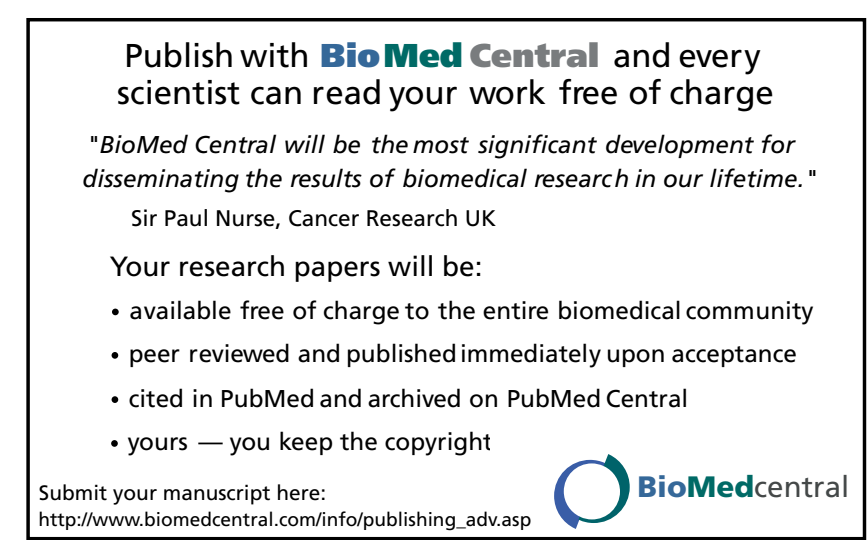

